\title{
THE NATURE OF JOINTING, TASMAN PENINSULA, SOUTHERN TASMANIA
}

\author{
by David Leaman
}

(with one table, four text-figures and ten plates)

Leaman, D.E., 1999 (31:x): The nature of jointing, Tasman Peninsula, southern Tasmania. Pap. Proc. R. Soc. Tasm. 133(1): 65-76.

https://doi.org/10.26749/rstpp.133.1.65 ISSN 0080-4703. Leaman Geophysics, GPO Box 320C, Hobart, Tasmania, Australia 7001.

\begin{abstract}
Existing literature describing the joints in high dolerite cliffs and at the Tessellated Pavement on the Tasman Peninsula offers conflicting views concerning their origin. Recent writers have preferred a tectonic origin. Although regional structures do affect both pavement and cliff rocks, these are not pervasive at outcrop scale. The rock pillars of the high cliffs are true, thermally produced columns, and their nature can be demonstrated by direct inspection of polygons. Polygon faces are not readily identified in collections of joint measurements, but some common orientations have been united in cliff exposure to yield ragged lineaments. This yields the illusion of more recent tectonic control, although many such orientations are clearly at least Jurassic in age. The apparently regular patterns of the pavements are regionally variable, and joint continuity and orientation are complex functions of lithology, bed thickness and pre-stressing, with new joints forming due to relaxation and weathering processes. Pavement joints are generally very recent although they too replicate much older structural trends controlled by east-west shears. Pavement ornamentation provides fine examples of physical and chemical weathering processes. Keywords: Tasmania, dolerite, columnar jointing, Tasman Peninsula, Tessellated Pavement, coastal weathering, jointing.
\end{abstract}

\section{INTRODUCTION}

Recent historical reviews of observations made by French and English explorers before 1803 and by some visitors, such as Charles Darwin in 1836 (e.g. Banks et al. 1989, Banks 1998, Banks \& Leaman 1999), drew attention to the manner in which important geological features on the Tasman Peninsula in southern Tasmania (fig. 1) have been described and interpreted. Two such features, much mentioned in early (pre 1850) references, are the Tessellated Pavement at Eaglehawk Neck in Permian siltstone and the great cliffs of Jurassic dolerite which extend around the southern coastline of the peninsula.

The joint patterns in each feature have been considered tectonic in origin, and the features have been linked in style and origin (e.g. Carey 1958, 1976).

Various propositions have been published as explanations for the tessellations and the associated joints, but none are supported by regional observations (Banks et al. 1989). This paper presents new information about the joints in the Pirates Bay area and suggests an alternative explanation.

Most other observers (including Forsyth 1984, Hergt et al. 1989, and the author) presumed that the joints in the dolerite cliffs defined cooling columns. This paper presents the first detailed inspection of the cliffs carried out in order to test the different concepts. Any conclusion is of general significance in evaluation of escarpments and mountain faces in central and eastern Tasmania.

\section{CLIFFS OF CAPES PILLAR AND RAOUL}

Early explorers sighting the enormous cliffs of Jurassic dolerite in southeastern Tasmania interpreted them as volcanic or basaltic (e.g. Flinders - Cape Basaltes=Cape Raoul [e.g. pl. 6]; Péron with Baudin - volcanoes rising out of the sea; Darwin - basaltic platforms). Banks et al. (1989) and Banks (1998) provided number of historical references. Every observer, whether French or English, noted the similarities in style and form to occurrences in the basaltic provinces in Europe and regarded the subvertical pillars of rock as columns - and consequently presumed a thermal, cooling origin for the features. It must be stressed that the gross identification depended on the observation of "columns" and the belief that these were due to cooling. Only the scale was abnormal.

After considerable debate during the 19th century, the dolerites were finally understood to be intrusive and postTriassic in age. The scale of the intrusions remained a surprising element, but the generation of columns during the cooling of large, sill-like intrusions was expected, based on analogies with thick basaltic flows, lava domes and vents (e.g. Hills 1963, Holmes 1965, Kelley 1987). Hills (1963: 362) actually cited the Tasmanian dolerites as exemplars of columnar jointing. This also seems to have been the prevailing view before Carey (1958).

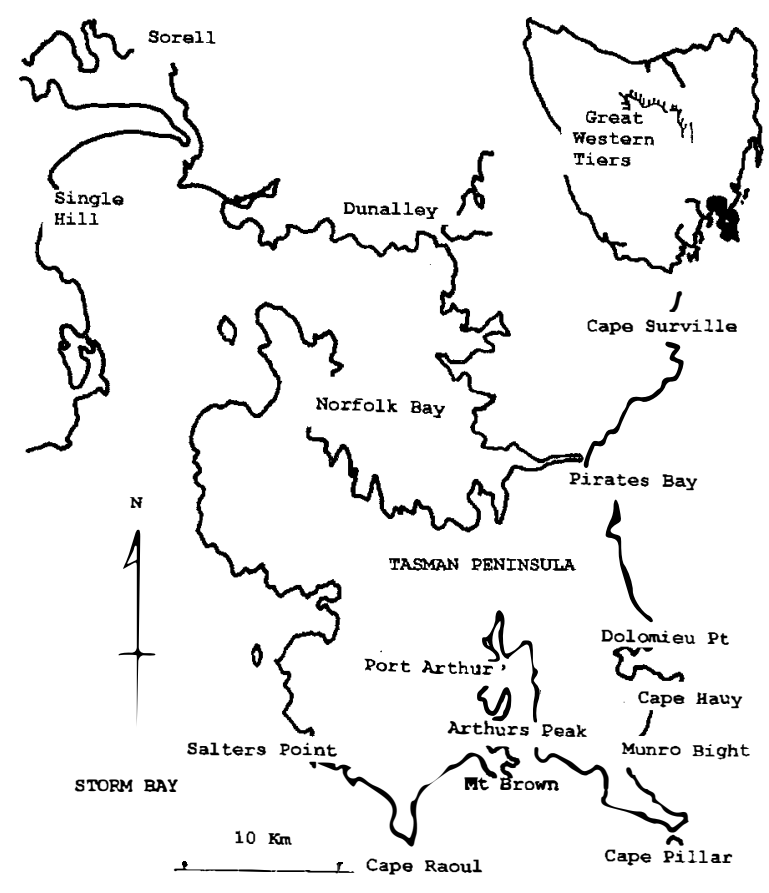

FIG. 1 - Locality map, Tasman Peninsula, southern Tasmania 
Carey, after examination of joint patterns as seen in aerial photographs (especially of the Central Plateau of Tasmania), claimed (1958:230) that in most exposures the "columns" are not usually hexagonal (as would be predicted theoretically if of thermal or shrinkage origin) but are controlled by two, nearly perpendicular dominant directions. Such joints were inferred to be epeirogenic and universal, not cooling joints. No evidence exists that Carey actually examined exposed plateau rocks, and few escarpments provide sufficient appropriate exposure to show detailed or columnar character in plan. The great cliffs are exceptions, as shown below. There is no doubt that, at regional scales, there are usually two nearly normal, penetrative joint systems, and that these could form the illusion of cooling columns.

Hale (1958) offered an alternate view. He considered that joints of thermal origin occurred at all scales and were commonly hexagonal and universal but were overprinted by an extensive conjugate (orthogonal) joint set. He noted that the latter was usually obvious, but that many thermal joints were unrecognised in surface exposures. Hale's study was largely based on underground observations. This view was supported by the detailed work of Hill (1964) at Mersey Bluff.

This conflict in the literature has remained unsettled, but Banks et al. (1989), in describing the origin of the cliffs and contained structures, stated

The columnar cliffs of dolerite owe their form to more or less planar fractures which may individually extend through tens or even hundreds of metres vertically to well over a kilometre horizontally and are spaced from less than a metre to well over two metres apart. Cooling joints some metres apart may be present in the centre of a dolerite body but only close to the contacts are cooling fractures obvious and there they are closely $(0.01$ to $0.2 \mathrm{~m})$ spaced perpendicular to the contact with much more widely spaced joints parallel to the contact.

Their view: the cliffs do not present true (thermal) columns.

Banks (1998) discussed the origin of the "columns" of the Organ Pipes on Mt Wellington and noted that these appear to be rectangular and not polygonal in section. The discussion noted that the origin of the columns has not been satisfactorily explained and referred to Carey (1958).

Hale (1958) and Leaman (1972, 1978) described the finer, tabular and clearly thermal joints related to contacts, but both authors (and Leaman 1997a) inset this character within a larger scale thermal and columnar context. Such thermal joints define prisms which have long axes normal to boundaries and a frequency governed by distance from contacts. All characteristics may be recognised in areas where other sources of tabular jointing (such as faults) are absent. All authors agreed with Carey (1958) that a platy joint system (closely spaced, generally orthogonal joints defining tabular slabs) may extend across the contact, depending on the sedimentary lithology and degree of metamorphism. Leaman (1997a), however, drew attention to columns up to $5 \mathrm{~m}$ across which extend to within a few metres of the top (Single Hill - pls 1,2) or base of intrusion (Nelson - Ridgeway Road); in these, the polygonal column faces can be distinguished from penetrative semiregional fractures and a complex of finer, internal and largely thermal joints. In each exemplary location, the nominal hexagons are apparent, the hexagon faces often display marked curvature and, where seen in massive rock, are often marked by a calcite or zeolite filling.

In many situations, for example above the Organ Pipes on Mt Wellington west of Hobart, it is difficult to assess the planar cross section of the rock pillars/columns. They may properly be called columnar cooling joints only if it can be shown that they are indeed thermal in origin. Fractures, fracture zones or parts of the rock mass may be infilled or covered with soil, debris or vegetation, and irregular outcrop relief may compound the problems of block, column or joint definition. Unless the actual "column" tops have been planed and eroded to remove soils and debris, the joint relationships cannot be discerned easily. This explains the uncertainty stated by Banks (1998).

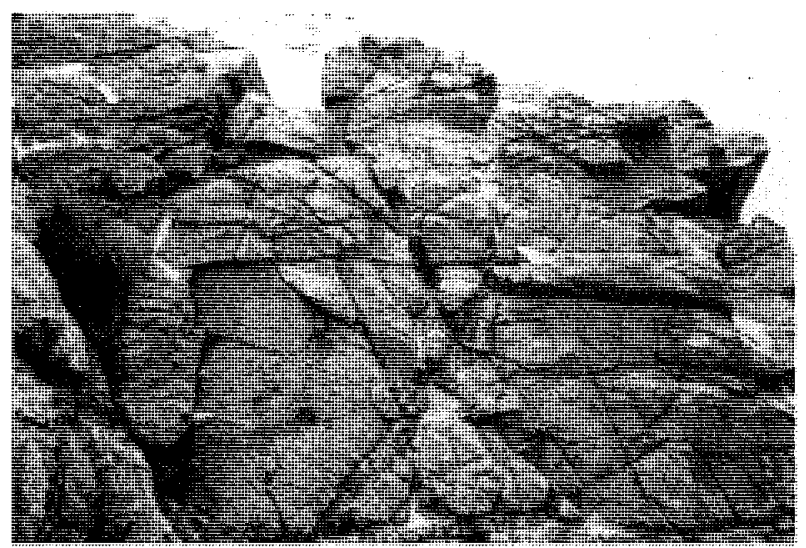

PLATE 1

Detail of column tops at Single Hill. Note the irregular overlapped pattern of the polygons and absence of regional trends and fractures. Most polygons are five- to seven-sided. Comparable character may be observed on cliffiops at Cape Raoul and Munro Bight, where columns are much larger. At such sites, all faces can be inspected, but in normal situations much of the detail is obscured by joint fillings, debris or soil cover. Patchy weathering profiles may also conceal this information. This section occurs within $3 m$ of the intrusion roof.

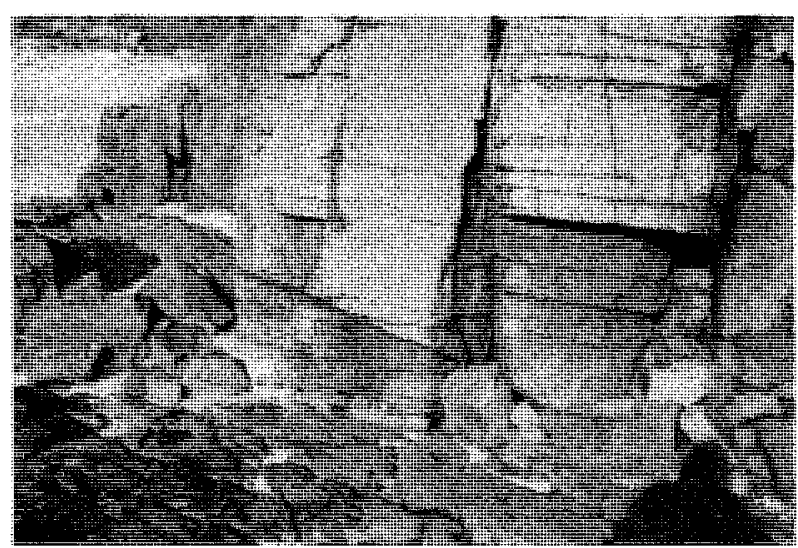

PLATE 2

View of columns shown in plate 1, Single Hill. Note the apparent square section, not confirmed in cross-section, and the frequency of tabular joints normal to the column axis. More recent low angle joints, considered to be true relaxation joints, which disrupt all others are also evident. 
Fortunately, most of the clifftops in southern Tasmania were planed and eroded prior to, or during, the last glacial epoch and then covered with a thin veneer of windblown quartz sand. This sand is clearly quite recent (Banks et al. 1989) and can be inspected at many sites (e.g. Perdition Ponds-Cape Pillar; Cape Raoul; above Salters Point; north Mount Brown - fig. 1). Dolerite weathering profiles are generally absent around the Tasman Peninsula, and the sand cover, which directly overlies fresh, massive rock, has been patchily and randomly removed in many places. The characteristics of jointing, prior erosion and sand cover may be observed at many outcrops on the Tasman Peninsula between sea level and $400 \mathrm{~m}$. A similar condition applies around the major escarpments of the Great Western Tiers in northern Tasmania, where different glacial period histories have produced similar results (but without the sand cover).

Cliff escarpments near Dolomieu Point, Cape Hauy, Mt Fortescue, Cape Pillar, Mt Brown, Arthurs Peak, Cape Raoul and Salters Point (fig. 1) and others near Pelverata (Snug Tier), Devils Throne (Wellington Plateau) and Mt Parmeener, Fisher Bluff and Devils Gullet (Great Western Tiers), Mt Jerusalem and Pillans Lake (Central Plateau) and Mt Olympus in northwestern Tasmania have been examined in order to establish generality and appraise Carey's 1958 comments. Many localities permit review of exposures at various levels within the intrusions and around nearby shore platforms. Hill (1964) already inferred that columns exist within a large intrusion and that a thermal entablature may be present, unrecognised, in many cases.

Faces in dolerite, whether natural or man-made, display an apparent tangle of joints and fractures. In the less common situation, namely that of the great escarpments, we often see a columnar regularity. In order to define the critical criteria able to separate the orthogonal or polygonal origin of the features it is necessary to consider some exemplary cases where all aspects can be evaluated, and then apply the findings to the more general and more inaccessible situations of the escarpments.

Columnar jointing of thermal origin was described at Single Hill and Ridgeway (Leaman 1997a). Consider what is actually present in these cases.

At Ridgeway, the columns are essentially four-sided, very large and basal to the intrusion. They also plunge shallowly northward and when broken present very hackly surfaces due to other, plentiful joints. One pervasive joint set, essentially the orientation of one column side, is oriented at $305-310^{\circ}$; not obviously related to local structures (intrusive margin or faults), it can be separated from thermal joints of essentially the same orientation, which curve and facet smoothly to produce small accessory faces. The other sides of the columns display most distinctive curved forms, and no other joint replicates this character. Each column retains its form and coherence, and most joints are trapped within its confines. It is possible to observe this at Ridgeway, due to a fortunate conjunction of joint dip and exposure face, but all other slopes in the region are smoothly eroded without scarps. Near the base of the columns and normal to them is another set of closely spaced joints, which mirror the dip and orientation of the intrusive margin. The Ridgeway case is complicated by the $30-40^{\circ}$ plunge of the columns, and no cross-sectional shapes can be examined. The diagnostic characters are considered to be the presence of confined joint packages and the curvature and facetting of large and small faces. Morphology is critical.
Single Hill provides a clear, diagnostic example of all factors - including the properties of contacts and associated sedimentary rocks - and the nature of the columns is evident in plates 1 and 2 . These do appear to be four-sided or rectangular at first inspection.

Examination reveals the following:

The columns are polygons with up to seven faces, of which four or five are predominant. They can be seen in crosssection and shown to almost wholly enclose a joint package; few joints (at 65 and $330^{\circ}$ ) cross polygon boundaries. Many joints with these orientations are incipient within the columns. There are many platy joints normal to the column axis (pl. 2) and these are also column-confined.

Figure 2 presents a summary of joint observations in different parts of this intrusion, showing that simple measurement of joints cannot resolve the issue at hand.

Near the roof of the intrusion, where the joints are very platy, different exposures yield distinctive patterns dominated by the near north-south (N-S) plates which dip steeply east (fig. 2A) or west (fig. 2B). Other important orientations (all younger joints) are at $65,285,330^{\circ}$. Within the intrusion, estimated at $100-150 \mathrm{~m}$ below the roof,
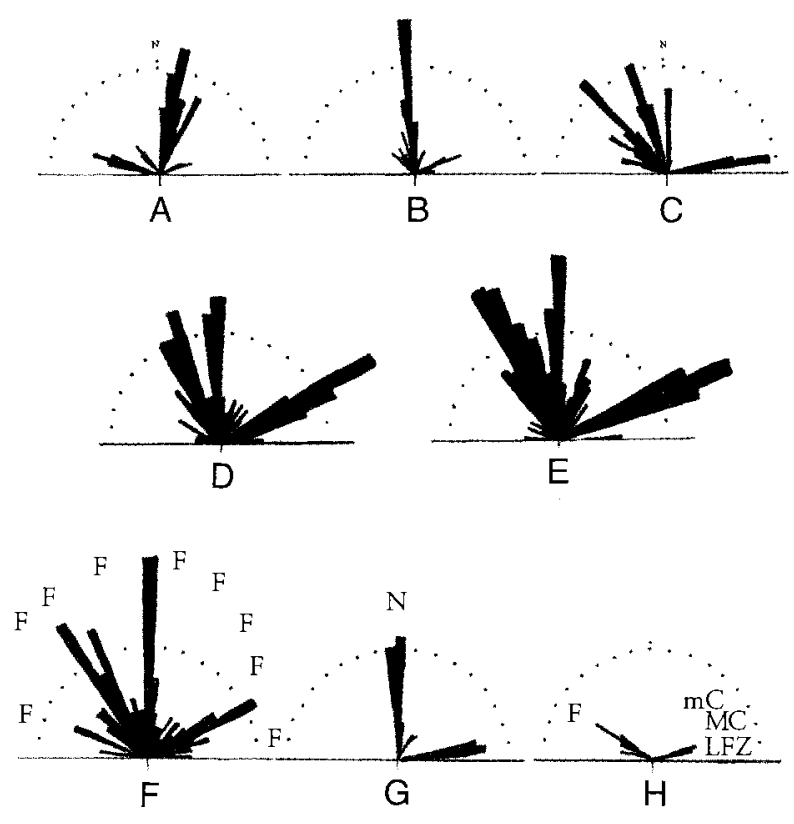

FIG. 2 - Joint characteristics at Single Hill. All characteristics of a typical dolerite intrusion can be assessed. (A) and (B) represent joints (each 100) from two large outcrops of finegrained dolerite displaying a predominance of platy joints, some of which are curved. $N-S$ joints at $(A)$ dip steeply east while those at (B) dip steeply west. (C) joints (100) with coarse-grained dolerite. (D) indicates all the joints (120) within a single-column cross-section by frequency of occurrence, while $(E)$ indicates the same joints (120) by total length. This shows that joints trending $335^{\circ}$, while numerous, are extended. $(F)$ presents a summary of joint frequencies (320) for many columns. The diagram also suggests the common orientations for column faces $(\mathrm{F})$. (G) displays the joints (66) observed within Fern Tree Group siltstones near site (B) while (H) displays joints (30) observed within Cascades Group/Deep Bay Formation above the roof of the main intrusion.

The orientations of faults, large fracture zones, major contacts and minor contacts are indicated by symbols F, LFZ, MC or $\mathrm{mC}$ respectively. 
predominant orientations are 80,315 and $340^{\circ}$ (fig. 2C). In the columnar zone (fig. 2D, E, F) predominant orientations are $0,65,80$ and $335^{\circ}$, which suggests a unity in orientations overall with local bias according to place in the intrusion. These orientations must also be seen in regional context: major intrusive (discordant) margins trend at about $70-75^{\circ}$, minor margins at $55-60^{\circ}$, faults disrupting the site are oriented at $285-295^{\circ}$, and other penetrative fracture zones are oriented at $80^{\circ}$. Large-scale rift faults, which bracket the Single Hill horst, trend approximately $\mathrm{N}-\mathrm{S}$. Joints in the intruded rocks inconsistently reflect aspects of these structures. Both the dolerite and Fern Tree Siltstone (fig. 2A, B, G) from the same area display the same N-S bias. There are very few joints in the Deep Bay Formation rocks $(2 \mathrm{H})$ even though extensively metamorphosed, and these reflect fault and contact orientations.

The diagrams do not indicate the most common joint orientation as shown in plate 2 - parallel to the intrusion roof and normal to the columns. Nor is it possible to identify the column faces in these diagrams. It is clear, in the Single Hill situation and almost certainly everywhere else, that many joints have an original thermal origin (as related to contact alignments), and others are associated with more recent faulting and epeirogeny.

Column faces, identified by polygonal form and facetted facing, are found to be oriented at 5-10, 20-25, 35-40, $50-55,75-80,285-290,320-325,330-335$ and $345-$ $350^{\circ}$. All these orientations appear in the rosettes, but some are rare overall and not recorded within the columns or rock mass $\left(20-25,35-40,50-55,320-325,345-350^{\circ}\right)$, although many contacts reproduce them $(50-55,75-80$, $320-325^{\circ}$ ). Further, some of these orientations yield major faces. It is usual to find that five to seven of the face angles provide major faces and the remainder provide facets or curved, linked surfaces; the selection differs from column to column and few orientations predominate. The association between column face orientations and intrusive margins shows that at least some of the features present in this intrusion are Jurassic in age and control (perhaps older). Since the N-S bias of figure $2 A, B, G$ represents the oldest joint system, it may well be that it also is related to the form of the intrusion and hence Jurassic in age. There are some examples of curvature in these joints. This could mean that the Tertiary rift faulting represents some rejuvenation of older structures.

This evaluation of well-exposed margins, joints, and parts of large and small intrusions shows that it is essential to know the setting and character of the intrusion before any assessment of joints can be made. A simple collation of joints without regard for boundaries or identification of type cannot be used to determine age, type or origin of joints in dolerite.

Review of these exemplary situations shows that any appraisal of the escarpments of the Central Plateau or the Tasman Peninsula must involve inspection of the actual shape of the columns.

Plates 3-6 indicate conditions near Fisher Bluff, Munro Bight and Cape Raoul. Every other situation is similar. Every rock pillar can be traced back from the escarpment and shown to be a four- to eight-sided (most commonly five- to seven-sided) polygon. Plates 1, 4 and 5 show that no gross or systematic joint system extends inboard of the escarpment face, and that joint patterns are defined by primary columnar shapes and other thermal joints within the defined columns. Persistent and continuous fractures do exist but they are the exception, not the rule, and their spacing must be counted in tens to hundreds of metres. The escarpment pillars are usually $1-5 \mathrm{~m}$ across (mostly $1-$ $2 \mathrm{~m}$ ). The polygon faces are often slightly curved and small facets appear on some corners. Each polygon may have about six large faces and up to four very small faces.

The cliff face on the north side of Munro Bight (pl. 3) is composed of jointed pillars which plunge steeply to the south. The surface exposures at the top of the cliff prove that these pillars are columns (fig. 3). This is one of the few sites on the Tasman Peninsula in which the columns stand some degrees from vertical, and their orientation reflects the shape of the intrusion, which is not concordant. The type examples at Single Hill and Mount Nelson (Leaman 1997a) show that column plunge is normal to intrusion margin. Figure 3 also shows the orientations of many hundreds of joints, as well as the column faces which form a minor subset. The major contact (unfaulted) in the area is oriented at about $80^{\circ}$ which accounts for many faces and other joints. Many coastal notches are oriented at about 40,335 and $350^{\circ}$, which are common face and joint orientations. Many cliff edges are aligned $25-35^{\circ}$, also represented by joints in the area. Note that no joint with any of the topographic alignments is generally penetrative and that many orientations are clearly Jurassic in age. Figure 3 does, however, suggest how notches and cliff edges may be defined with or without an additional fracture system. The columnar faces do have an alignment bias toward orientations of about 85 and $330^{\circ}$, and it is hardly surprising if these cliff edge orientations develop as the rock mass is eroded. At least one of these orientations, which produces the cliff face on the north side of Munro Bight, is determined by the intrusive margin. Neither of these two nominally orthogonal orientations represents a penetrative or epeirogenic joint but, where the exposure is poor, they could appear to do so.

The ragged faces shown in plates 4 and 6 could be generated by a regional fracture which has cut across columns but may also be produced by an inherent bias in face angles.

These observations suggest that neither Carey (1958) nor Banks et al. (1989) were justified in assigning general tectonic fracturing as the explanation for the columnar appearance. The rock pillars are generally true thermal columns. Further, scale is important. Carey (1958) could recognise (or infer) large fracture systems only at photo scales - but not the column pattern - and concluded incorrectly. It may yet be found that many of the gross trends are, in fact, rejuvenations of orientation bias within the columns and not tectonic, given the suggestive correlation between the face orientations at Munro Bight and the marked clefts along the Bight to Cape Hauy.

Studies of several cliffs have also revealed aspects of thermal history. Many intrusions are multiple and apparently "layered" (e.g. Single Hill, Leaman 1997a). The intrusion at Cape Raoul is such a body. In each case, the columns extend across the textural and compositional variations (pl. 6). Many internal contacts show that previous intrusions were often hot, but already crystalline, with minimal chilled margins. Detailed inspection of joints near layer junctions shows that an hierarchy exists. Some early formed joints do not propagate in the next layer and often contain a mineral fill (calcite, zeolite). Many are platy. The principal columnar joints propagate throughout the entire intrusion independent of layering variations, and this 


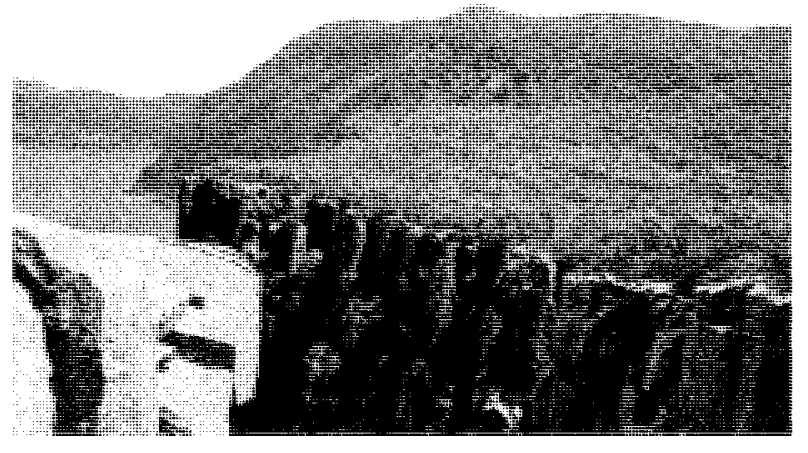

PLATE 3

View of cliff edge in Munro Bight west of the Monument Lookout. The cliff alignment shown is oriented at about $335^{\circ}$ while the general alignment of the cliff is oriented parallel to the main discordant margin $\left(80^{\circ}\right)$.

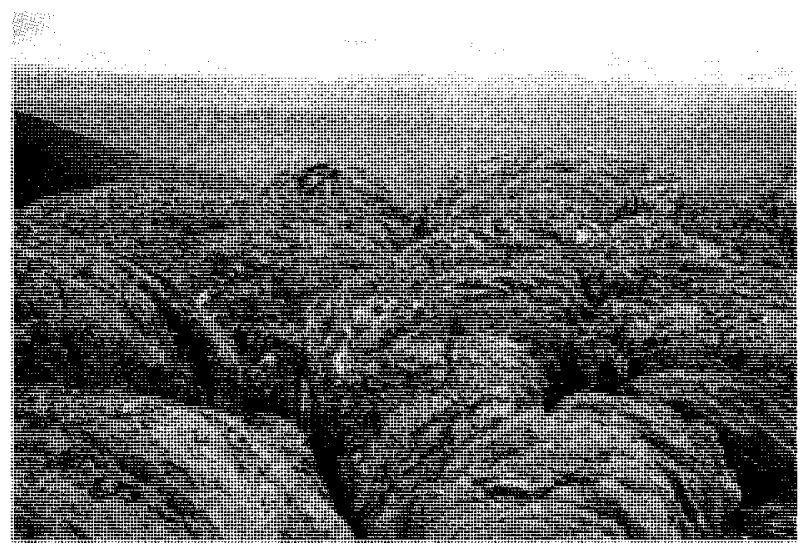

PLATE 5

Detail of column tops at Fisher Bluff. Note the irregular overlapped pattern of the polygons and absence of regional trends and fractures. Most polygons are five- to seven-sided. Comparable character may be observed on clifftops at Cape Raoul and Munro Bight. At such sites all faces can be inspected, but in normal situations much of the detail is obscured by joint fillings, debris or soil cover. Patchy weathering profiles may also conceal this information.

behaviour is most clearly demonstrated at site $A$, Single Hill (Leaman 1997a, fig. 4). These observations confirm that columns form late in the intrusion and cooling cycle, and that polygon formation, once begun, can be imposed on newer injections, provided the injection period spans only a small proportion of the total time required for complete cooling (to below $300^{\circ} \mathrm{C}$ ). One hundred thousand years can be allowed for column formation, and the rate of heat loss is not radically modified by incremental, additional injections while all the material remains warm or partly crystallised (Jaeger 1958).

\section{JOINTING IN OTHER IGNEOUS ROCKS}

Several comparable deductions have been made in other igneous rocks (thick lavas and granites). Segall et al. (1990) showed, on the basis of dated fillings, that fractures form

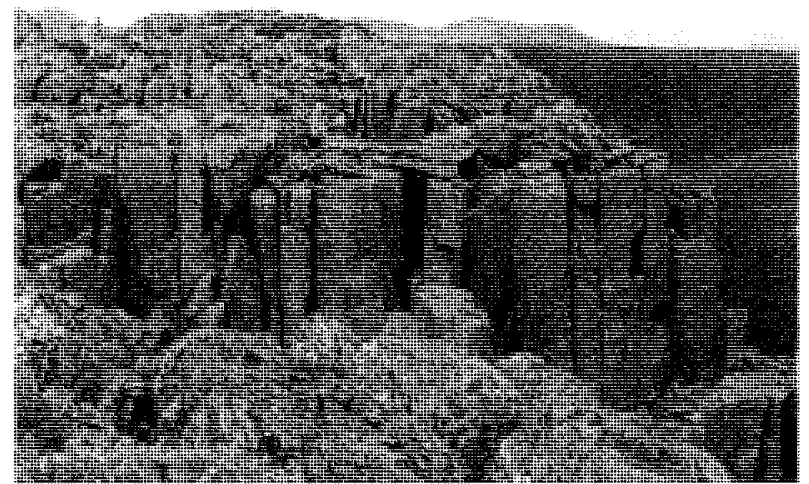

PLATE 4

Columns and eroded surface near Fisher Bluff, western edge of Central Plateau. Note that the column faces appear rectangular but that no fracture trend can be traced from the scarp into the rock mass. All columns average 2-3 $m$ across and appear to be rectangular (pl. 5).

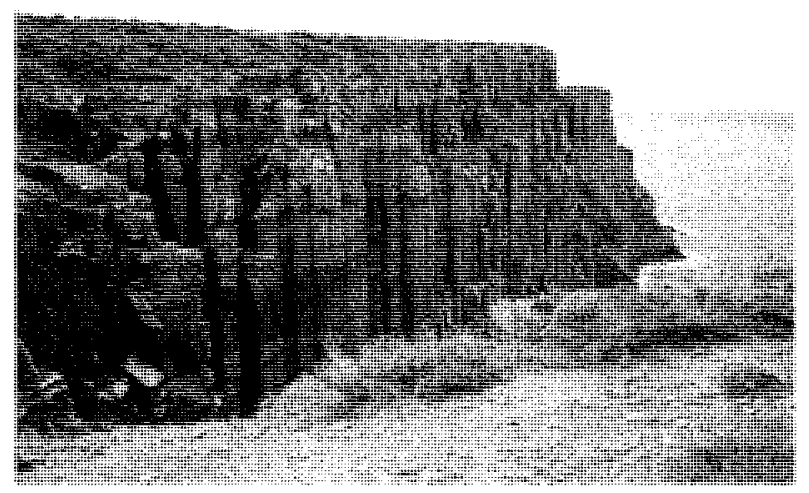

PLATE 6

"Layered" dolerite on west face of Cape Raoul. Columns are continuous and unaffected by variations in lithology. Cliff is over $200 \mathrm{~m}$ high at this point. Columns are typically $2 \mathrm{~m}$ wide. The cliff alignment has the appearance of a fracture control but the effect may be due to a column face orientation bias.

within large granite intrusions as the rock cools. Common joints in the Sierra Nevada granites are nearly parallel (not forming polygonal systems) in the style of Single Hill (fig. 2A, B). Segall et al. (1990) inferred a bias applied by lithostatic or tectonic forces during cooling. Segall \& Pollard (1983a,b) and US Geological Survey (1984) suggested that faults (or master fractures) may evolve from original joints where some orientation bias already exists. The Munro Bight and Cape Hauy dolerite provides supporting evidence for such a concept. The Munro Bight joint pattern (e.g. fig. 3) matches the irregular polygonal form (non-hexagonal) in the classification of Pollard \& Aydin (1988).

The variation in four- to seven-sided character, and the apparent four-sided visual appearance (noted near margins at Ridgeway, Single Hill and inferred by Banks et al. 1989 overall), may be consistent with observations in thick flows, where there is often a general change in form from four- to six-sided character depending on position within and 


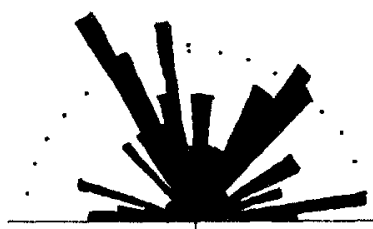

A

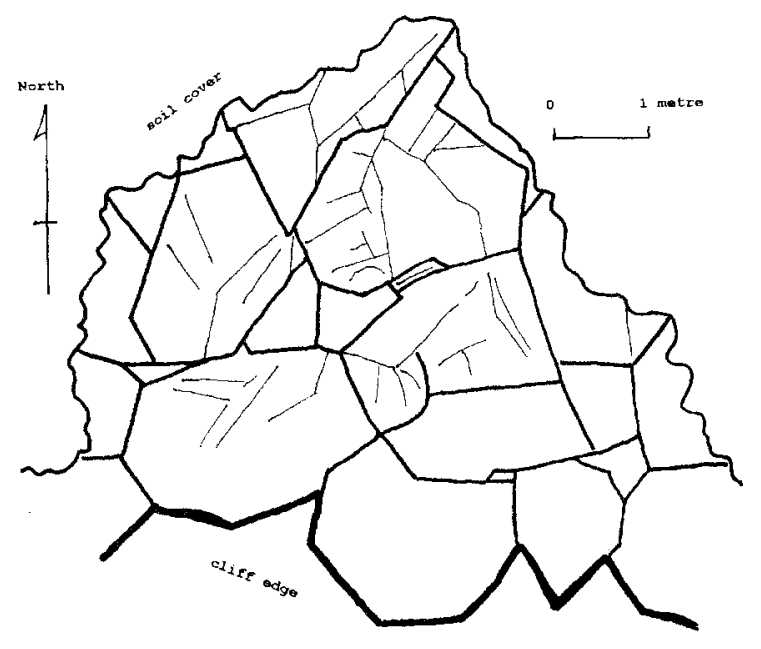

FIG. 3 - Joint patterns on north side of Munro Bight, west of the Monument Lookout. (A) displays all the joints (160) in the region of the cliffedge section while $(B)$ presents only those joints (52) recognised as column faces. The map indicates a typical joint pattern in plan. Note the way in which even this short section of cliff face has developed a hackly but generally systematic alignment just south of east. Other clefts in this cliff emphasise the face alignments at 40 and $330^{\circ}$. Note that there are no cross-cutting fractures in this exposure.

thickness (Aydin \& DeGraff 1988). DeGraff \& Aydin (1993) related the size of columns and spacing of all joints to the rate of temperature change. It is not yet clear if this is true of Jurassic dolerites, but depth of burial at the time of intrusion may be important since there is a difference in overall joint character between dolerites intruded into Permian rocks and those intruded into Late Triassic rocks (Leaman 1997a).

\section{THE TESSELLATED PAVEMENT}

Banks et al. (1989) outlined the history of visitation to, appreciation of and publication about the jointed shore platform at Lufra, Eaglehawk Neck (site D, fig. 4). The site, now protected and visited by thousands each year, is a representative shore platform within the Pirates Bay region. A smaller pavement nearer Clydes Island (also noted by David \& Browne 1950) is actually a finer and more compact example (site C, fig. 4).

The term "tessellated" is here taken to refer to the fine patterns exposed (Oxford English Dictionary) and not to any direct affinity with tiles. There are many subtle variants within the patterns which are not tile-like. The two fine pavements are not unique, but inspection of the coastline does show that good examples of the possible patterns are rare, and it is clear that early visitors were impressed by the quality of display at Eaglehawk Neck. Plate 8 exemplifies the finest pattern.

The pavements around Pirates Bay, all in members of the Permian Malbina Formation (Clarke 1989), have been formed since sea levels stabilised a little more than 6000 years ago. There are indications of an eroded, higher level surface about $1 \mathrm{~m}$ above present mean sea level. The Permian rocks are interbedded pebbly siltstones and sandstones. Individual beds tend to be compositionally uniform and up to $600 \mathrm{~mm}$ thick, but some are very thin and fissile. Each bed of these poorly sorted rocks is fairly uniform overall but is individually distinctive in both texture and grain size.

\section{Microtopography of the Pavements and its Origin}

Banks et al. (1989) outlined previous theories for the origin of the tessellations (pl. 7); tile pans (pl. 7), loaf-of-bread (pl. 7 front) and pane-of-glass (part pl. 8) effects. The finest form (pl. 8) has the appearance of dressed stone with a finely chipped margin and a coarsely chipped interior. Banks et al. and the present writer concluded that intertidal coastal abrasion, coupled with salt infiltration and expansion upon crystallisation, can explain all effects, including the spongy surface textures and elephant-skin weathering observed. Elephant-skin weathering may also be related to whole rock changes upon weathering, or local expansion and contraction due to wetting and drying. This salt-based weathering process steadily increases porosity and leads to loss of original cements or matrix. Most pitted surfaces reflect this action. Most change occurs about joints, which act as conduits, vertically and laterally, for fluid flow, and wall rock alteration is greatest along them. Alteration distance from the joints varies across the site and clearly depends on changes in porosity effected by water penetration and the particular properties of the bed. This process commonly leads to engravure along the joint, as cement or matrix is removed and grains can be separated. Where water can pass freely or stand, the etched zone is widened and flattened to produce the classical "dressed stone" pattern edge margin (pl. 8). The relationship between joint capacity (to transfer fluid), intertidal level, actual rock composition and porosity, rock dip (which controls rates of infiltration or evaporation) and prior fluid history (which may have variably altered primary properties) controls the rate of rock destruction and hence the particular style of weathering which results. Exceptional situations arise where chemical exchange occurs, and iron oxides can be precipitated. Iron oxides tend to act as a firm cement and filling and are also more resistant to further physical or chemical weathering than the unaltered or partly expanded host rock.

All processes and exchanges are clearly modern. These rocks may never have contained a cement, as such, but compression of the fine matrix on compaction may have achieved a comparable result. Iron sealing may be restricted to the joint itself or be evident in colouration up to $50 \mathrm{~mm}$ from the joint. All joint sets are affected by all processes; thus, iron oxides may be found in any joint set at any location. Only a small proportion of joints is iron-sealed or modified at any site. Joints filled with iron oxide are more resistant, and the selvedge of rock adjacent to them may be elevated; this contributes to the formation of the panes-ofglass effect when water can rest on the blocks. 


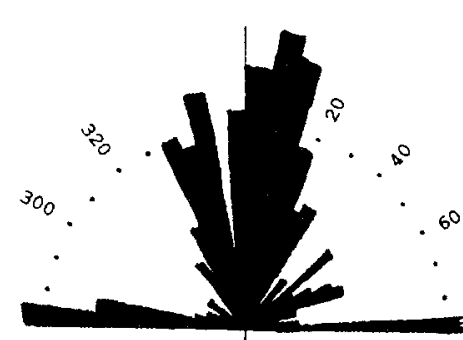

(all joints in region)

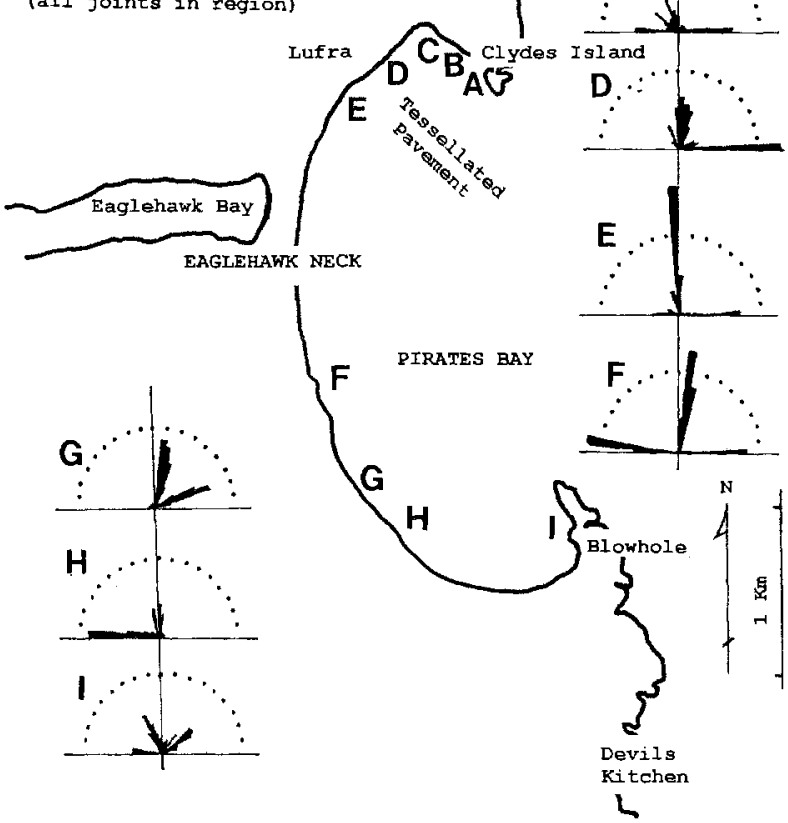

FIG. 4 - Location of jointed pavements in Pirates Bay region. Each rosette represents 100 joints (except $C-170$ joints) for a pavement segment. The rosettes have been plotted by $5^{\circ}$ intervals and marked for each $10^{\circ}$. The markings are provided at 20\% measurement weight. The large rosette is a compilation of all sites.

Inspection of many pavements has also revealed the rarity of the true dressed-block effects (pl. 8). Such effects are only well developed near sites B and D (fig. 4).

\section{The Origin of the Joints}

While this discussion suggests the nature of the origin of the present display, it does not resolve the issue of the origin of the joints themselves; whether these are formed as part of the weathering cycle or control it.

The nature of the joints

All joints, even newly-formed features, are well defined physically (pls 7-10).

Several features may be noted at the Tessellated Pavement. (1) Spacing or orientation of parallel joints is not clearly related to grain size or bed thickness but may vary between 100 and $750 \mathrm{~mm}$ in most beds regardless of character. The spacings are typically between 200 and $500 \mathrm{~mm}$ in siltstones. (2) Joint terminations are complex (pl. 9), displacements are negligible and not systematic, and joints break pebbles of all sizes. Joints are developed synchronously.

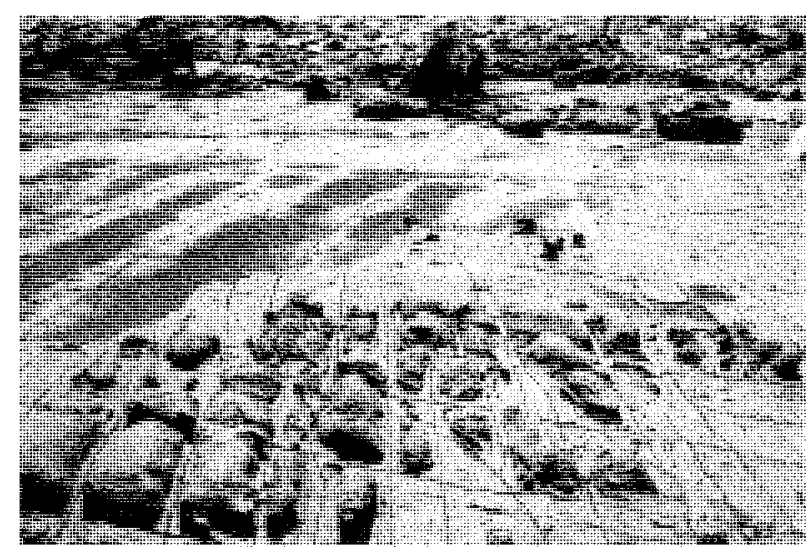

PLATE 7

Part of mini pavement (site $C$, fig. 4) at Pirates Bay. Note the change in character from bed to bed. Bed in foreground shows loaf-of-bread character. Joints on underlying bed are acute to main trend on upper layer and conjugate set is absent. View looking west. Joints facing the camera are 200-300 $\mathrm{mm}$ apart.

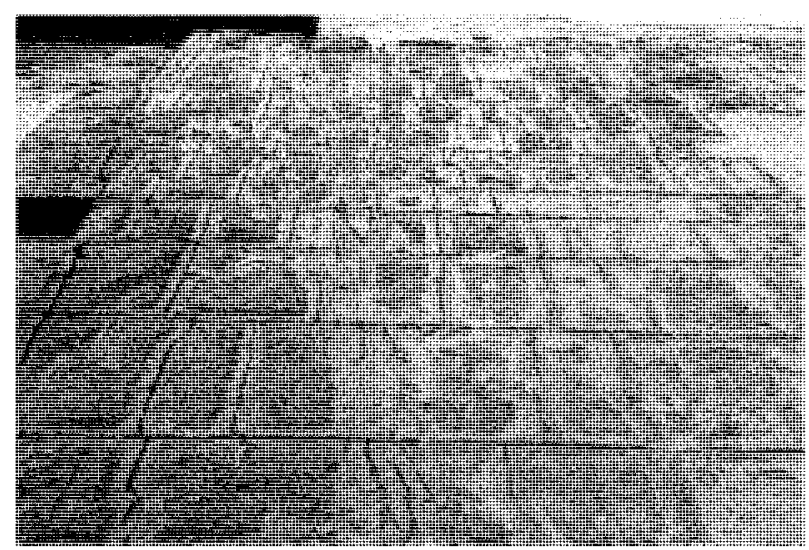

PLATE 8

Typical example of Tessellated Pavement (site D, fig. 4), much as illustrated by many authors. Note the tile format, etched joints and some pane-of-glass effects. Observe that joints extending from left to right are extended, while those facing away from the camera are much more segmented. Note the single large, braided fracture which disrupts all other features (and penetrates all beds). View looking north.

(3) Many orientations are recognisable in newly formed elephant-skin cracks, and these can be shown in various stages of interconnection to yield new fractures within existing tessellations.

(4) At least two joint sets occur in all layers, but some beds contain at least one additional joint. All joints are subvertical. (5) Some subhorizontal joints are visible in more fissile beds, and only a small proportion of joints of any orientation extend through any bedded sequence.

(6) Not all joints or members of any joint set consistently affect more than the exposed bed (pls 7, 10). Many joints are restricted to a single bed.

(7) Most joints, including newly formed surface cracks, open upward and show no suggestion of an incipient fracture deeper within the bed affected. 


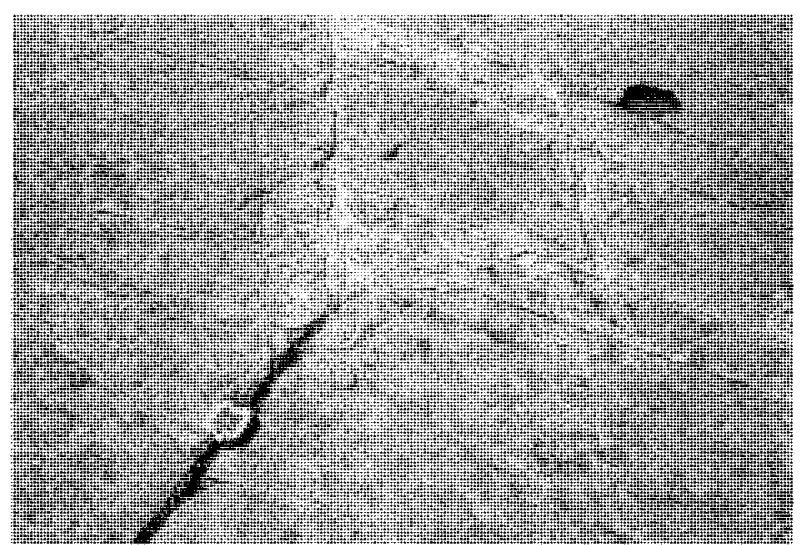

PLATE 9

Example of interrelation of joint systems (site I, fig. 4). Regular patterns are developed in each subzone about the complex triple point. Many small offsets have been recorded along each joint set at every site; yet no consistent pattern of age or relationships can be assigned. Features such as this triple point show that all fractures are contemporaneous and grow intermittently as an entire group with exposure and modern weathering (with consequent expansion of the rock mass). View looking east.

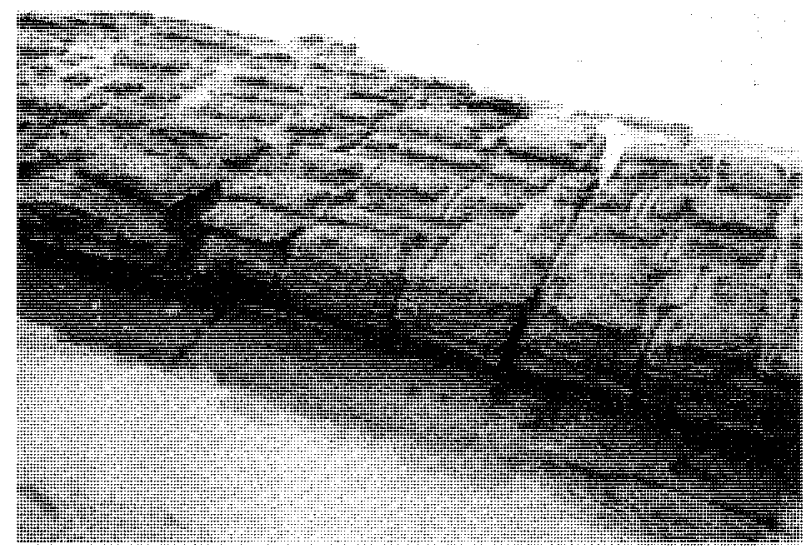

PLATE 10

Part of pavement at site E (fig. 4). Note that only one in three or four of joints facing the camera actually passes into the underlying bed. Many other sympathetic joints are shorter or within tessellations. View looking south.

\section{The local structural background}

The rocks exposed around Pirates Bay are, in regional context, virtually flat-lying; dips rarely exceed $3^{\circ}$ although strike is variable. There is no system to dip variations around the bay; most changes may be due to minor bed rotation near faults - there being several small faults in the bay area, especially north and east of Lufra and the main tessellated pavement. It has been suggested that a small anriclinal fold is present at the north end of the bay and that the bisectrix or joint orientation is consistent with this (Banks et al. 1989). It is not possible to evaluate these explanations due to lack of exposure.

\section{Joint directions}

Banks et al. (1989) stated that the common joint directions are about 330 and $75^{\circ}$ with a bisectrix at $295^{\circ}$. An additional joint $\left(15^{\circ}\right)$ was found in some beds. Dr M. Banks (1996, pers. comm.) revised these details as follows: $0,13,89^{\circ}$, bisectrix $51^{\circ}$. Theselatter directions, but not those published, can be replicated (site D, fig. 4). Further examination suggested that the results might be site specific. Carey $(1958,1976)$, however, implied that the joint system was regular, regionally coherent, mirrored by the dolerite joint system and penetrative.

The first part of this paper has shown that significant parts of the dolerite joint systems are predominantly thermal in origin while preliminary inspection at the pavement suggested that many joints may be neither coherent nor penetrative as implied by Carey (1958: 229).

Detailed measurements, therefore, were undertaken at nine platforms around Pirates Bay, in order to fully test Carey's (1958) proposition and the comments of Banks et al. (1989). Approximately 1000 joints were measured; for orientation, continuity, character and bed penetration. The results are summarised in figure 4 and table 1 . Continuity is defined as the minimum continuous visible length of joint. Not all joints are fully exposed; many pass into cliffs or to seaward and many pavement joints provide an illusion of length, although present as relatively short segments $(1-3 \mathrm{~m})$ not connected to other joints of similar orientation. Tessellations may appear surprisingly regular or perfect from a distance and yet be found to be based on quite irregular joint associations, when examined closely. It is the consistency of interlocking trends, not the orthogonal continuity of particular fractures or joint pairs, which produces the overall effect (pl. 8).

Observations of joints has included a description of the type of breakage; some orientations appear as simple, planar breaks, others are compound fractures (centre of pl. 6, trending from the camera) and may feather or include small en echelon fractures in a narrow band. Some joints are curved, and a range of surface characters may be observed; most are straight with smooth surfaces.

Bed penetration was checked for all joints which extended across a platform or bed edge, or into a cliff face.

Measurements were made on a segment of each platform within a $15 \mathrm{~m}$ radius of a randomly selected point. All joints longer than $300 \mathrm{~mm}$ were measured. It should be noted that many smaller, isolated fractures do exist. Therefore, any simple correlation based on frequency of occurrence may be misleading, since the measured area may contain only 20 joints at one pronounced orientation and 60 at another (as in pl. 8). The effect may still be tabular, but the continuity, character and penetration factors may be quite different. The rosettes of figure 4 should only be used to suggest dominant orientations and not necessarily significance or importance of trend. Each rosette is expressed in terms of percentages of joints within the sampled area.

Figure 4 shows that there is great variability in trends around Pirates Bay. There is no regional coherence other than the general presence of a near east-west (E-W) element. North-south elements are much more patchy and inconsistent. This conclusion can be established by consideration of scale and character (table 1). A compilation of all measurements is shown in the large rosette in figure 4. The dominant trend is E-W with subsidiaries at about $10^{\circ}$ and $345^{\circ}$ and a bisectrix around $50^{\circ}$. This compilation 
TABLE 1

Summary of characteristics of joints around Pirates Bay*

\begin{tabular}{|c|c|c|c|c|c|c|}
\hline $\begin{array}{l}\text { Platform } \\
\text { site }^{\dagger}\end{array}$ & \multicolumn{6}{|c|}{ (joint orientation package) } \\
\hline A & & c3common & & a5some & & b0.5rare \\
\hline B & & c4common & & a2rare & & bl.5rare \\
\hline $\mathrm{C} 1$ & & & & al0rare & c0.3rare & b4rare \\
\hline $\mathrm{C} 2$ & a4́rare & & & b4rare & cl.5rare & \\
\hline $\mathrm{C} 3$ & c0.7rare & & & a3rare & clrare & b9rare \\
\hline $\mathrm{D}$ & b4rare & & & al2some & & c0.7rare \\
\hline $\mathrm{E}$ & alrare & & & b5some & & c0.5rare \\
\hline $\mathrm{F}$ & a9some & & & b12common & & \\
\hline $\mathrm{G}$ & a3some & & b8some & c0.6rare & & \\
\hline $\mathrm{H}$ & blsome & & & a9common & & cl0common \\
\hline I & & & a $10 \mathrm{common}$ & b3rare & & cl.5rare \\
\hline
\end{tabular}

* Each comment is in three parts, $\mathrm{XnY}$.

$\mathrm{X}$ is a measure of the relative dominance of the joint: $\mathrm{a}=$ very common, $\mathrm{b}=$ less common, $\mathrm{c}=$ not common. $\mathrm{n}$ is the average length in metres of joints of that orientation (minima for long joints).

$Y$ is a comment to indicate how often joints of the given orientation pass continuously between beds: rare implies that the joint is usually confined within a bed;

some means the joint set may occasionally continue into the adjacent bed; common means that the joint set usually continues into the adjacent beds.

Joint spacing is not diagnostic.

$\dagger$ Sites as in figure 4; characteristics of individual beds are presented for site C.

tends to stress the $\mathrm{N}-\mathrm{S}$ character regionally and yet, seen in detail as subsets, it is neither universal nor consistent. This suggests that joint assessments which do not consider the source of data, and variations within it, might be misleading. No geographical domains can be constructed from the measured sites, although variations between sites $A$ and $E$ might be related to $\mathrm{N}-\mathrm{S}$ faulting. Such fault-controlled patterns cannot be matched on the southern side of the bay, a fact which might reflect distance or the presence of sub E-W faults south of site E. Major N-S fractures and small faults can be observed parallel to the coast south of site I and yet there is no reflection of this orientation in data from this site.

Table 1 shows the "classic" pavement to be both typical and atypical. It contains the three most observed trends (within a narrow envelope) but not in consistent proportion or importance. Few of these trends are consistently penetrative, although casual inspection of adjacent cliff faces might suggest otherwise. Many joints are only present on the upper surfaces of beds or exposures, with no suggestion of any expansion of pre-existing cracks indicating a weathering and relaxation process for their origin. Only compound, complex joints made up of a net of interwoven smaller fractures (such as facing camera in pl. 8) are truly disruptive and these may be the only true epeirogenic joints; their spacing is irregular.
The joint trends observed may be contrasted with fault or gulch orientation. Major faults and fractures in the region are oriented at either $355-360^{\circ}$ or a stepped combination of $80-90^{\circ}$ and $65^{\circ}$, and the overall effect is that of structures trending a little north of east north of Eaglehawk Bay or a little south of east south of Eaglehawk Bay. Eaglehawk Bay represents a gross feature of this type. Where large E-W structures can be inspected on shore platforms, each is seen to consist of long fractures extending E-W joined or offset by shorter fractures oriented at $65^{\circ}$. Such offsets are noticeable at sites B, D, G and I. This behaviour is consistent with dextral shear and might well locally yield sub N-S fractures.

\section{Joints and regional structures}

Regional faults (Leaman 1997b) occur with trends at approximately $5,65,290,310,330$ and $350^{\circ}$. The principal structure in the region, a concealed granite margin and associated dolerite feeder, trends approximately $\mathrm{N}-\mathrm{S}$ beneath the Eaglehawk Neck area. Structures near and above this margin were demonstrably active during Jurassic and Tertiary times (Leaman 1997b) and may have been active during, or soon after, deposition of the Permian cover rocks. It is possible that local thickness changes within the Permian rocks are related to such activity, and stress variations would have been imposed on the sequence, due to subsequent compaction. 
The absence of any major major E-W faults, the likely shear character of E-W features, and the possible effect on production or reopening of $\mathrm{N}-\mathrm{S}$ fractures and association of feeders suggest that most of the structural controls are ancient but may well be subject to modern rejuvenation. The sub N-S joint system is almost certainly related to stresses which were imposed soon after deposition and which continue to re-activate the granite margin. Several small N-S trending faults can be found south of Pirates Bay near the coast. Any stresses may have been moderated during time, due to continental margin rifting and uplift throughout the last $70 \mathrm{Ma}$, or to pulsed compressions of the type described by Davidson (1997). Recent (c. 1985) seismic activity near Bream Creek was focussed on a portion of the granite margin, and the shape of the eastern coastline of Port Arthur to the south is also consistent with longterm, minor activity. No large-scale structures, other than dolerite intrusions, have been observed along this entire marginal zone. The E-W system is certainly regional as described above (although no known fault has this orientation in this area) and has been recorded (at about $80^{\circ}$ ) in many data sets covering eastern Tasmania (e.g. Leaman \& Richardson 1990). Each erosional gulch along the coast has formed where several E-W fractures are grouped. All other regional trends, as listed above, occur on the Forestier Peninsula, but most are unknown in the Pirates Bay area.

Joint spacing was noted at all sites but was found to be a non critical criterion or descriptor. Most joint sets, regardless of continuity or appearance, present similar spacing ranges (100-500 $\mathrm{mm}$ for well-developed character; $10-100 \mathrm{~mm}$ for incipient character). Only complex systems (described above, pl. 8) or groups of E-W fractures may offer useful spacing data, but such compound systems are rarely less than $10 \mathrm{~m}$ apart and may exceed $50 \mathrm{~m}$ separations.

\section{How old are the joints?}

Many joints are now in formation as a result of unloading by erosion and weathering. These are present as splinters or isolated fractures within tessellated blocks. Elephant-skin texture occurs at various scales on many block surfaces. The formation of minor fractures must represent whole rock expansion and not simply regional stresses; yet the orientations are consistent with, or are affected by the local, developed joint sets. This implies some degree of prestressing within the rock mass. New joints grow to connect and expand the tessellation pattern, even as erosion levels and removes coastward portions of beds.

Branagan \& Cairns (1993) have described similar surfaces in Triassic sandstones. The fractures rarely extend more than $200 \mathrm{~mm}$ into the rock and were inferred to be due to weathering and erosion processes on an old landscape. Thermal expansion/contraction was proposed as the likely cause, the presence of an expandable clay an additional swelling factor. It is not known which clays, if any, are present at Pirates Bay, but salt-related alteration and swelling processes are active.

The small pavement at $C$ (fig. 4) was examined in greater detail and all joints measured were identified by bed. Three beds were inspected and the summation of all joints at the site is given in figure 4 . Each bed could be described as a pebbly siltstone and not readily distinguished from its companions. Some striking differences (table 1) were noted and some of these can be seen in plate 7 . Two beds (C1, C3) lack the near $\mathrm{N}-\mathrm{S}$ joints, while all beds preserve the
E-W joints. Beds $\mathrm{C} 1$ and $\mathrm{C} 2$ record trends about $300^{\circ}$, while beds $\mathrm{C} 1$ and $\mathrm{C} 3$ reflect trends about $340^{\circ}$. Only bed $\mathrm{C} 2$ carries $\mathrm{N}-\mathrm{S}$ and $\mathrm{NE}$ trends. This variability, lack of vertical continuity and also change in spacing (evident in the plate) and length show that lithology and the physical characteristics of the beds are important. There is no suggestion that these rocks were stressed and fractured when confined and buried to produce a coherent regional, tectonic fracture system of the type implied by Carey $(1958,1976)$.

Many joints pass from subvertical in the local bed to subhorizontal near the first bedding parting, which, also, is usually fissile and expanded by weathering, alteration or relaxation. There is little sense in which this rock sequence could be said to have been stressed and fractured as a package; nearly all effects are surficial.

Finally, it can be shown that, in any given pavement, the ternary joint grouping (few pavements approach binary patterns, although the finest tessellations occur where this situation is approximated) develops concomitantly (pl. 9). Various patterns of offset and movement can be assigned on any pavement, but none are consistent either within a pavement or with other pavements. All observations on the pavements are consistent only if joints have grown synchronously within the exposed weathering environ ment. Although the pavement joints display more regularity than those described by Branagan \& Cairns (1993), the origin must be similar. The regularity, persistence and recurrence of orientations suggests a prestressed condition controlling each joint set. The basic stressing, active since at least the Permian, is a fundamental E-W shear with a derivative $\mathrm{N}-\mathrm{S}$ component. Most joints form only on unloading (as suggested by Banks et al. 1989) in such a stress field, with results modified by bed thickness, strength and susceptibility to weathering.

The much appreciated, delicate block pavements - with their variations in decoration - are relatively rare and must reflect bed composition and particular, chemical weathering processes, or perhaps rate of application of process.

\section{CONCLUSION}

Examination of jointing at the well-known coastal features on the Tasman Peninsula has shown that there is no simple ruling, regional scheme.

Persistent regional joints are relatively rare, although present in the dolerite of the high cliffs and on the siltstone shore platforms. Such joints are widely spaced; commonly at $2 \mathrm{~m}$ to more than $50 \mathrm{~m}$ but consistent in orientation. These are approximately $\mathrm{N}-\mathrm{S}$ and $\mathrm{E}-\mathrm{W}$ near Pirates Bay, but it is difficult to judge consistently whether topographic features truly reflect regional joint systems elsewhere.

For example, the dolerite cliffs are dominated by true columnar joints of thermal origin, disrupted in places (and apparently) by more regional tectonic fractures. The primary columns approach hexagonal ideals and are of similar size, regardless of position within the intrusion. Detailed inspection of many outcrops, whether at clifftop, in ravines or on shorelines, shows that, irrespective of irregular terrain or uneven presentation of surfaces, these thermal forms can be identified. Many other lesser thermal or tectonic fractures may attract the eye of the observer and falsify the impression. Review of sites suggests that some topographic alignments have been produced by selective erosion due to slight 
biasses in the orientation of column faces, even though there is no actual penetrative fracture. It is possible that regional assessments might infer such fractures when none exist. Observations at Single Hill and Munro Bight show that near-orthogonal patterns apparently can result from primary joint bias. Such a bias in thermally generated joints might well have regional control (crustal controls on feeders, stresses or intrusion form), and the effect will then be rejuvenated. Carey's $(1958,1976)$ conclusion about regional character might then be valid in these terms, but his implication that the visually striking columns were themselves shaped by a regional, orthogonal joint set of tectonic origin is not. Hale (1958) essentially made this point, and Carey (1958), working at a different scale, did not recognise the disguised character of visual interactions involved. His mistaken view has prevailed and persisted into more recent literature. Hills (1963) was quite correct to suggest that the Tasmanian escarpments offer superb examples of true columnar form.

The study has also shown that collection of joint measurements, without due regard to contacts, known faults, recognisable column faces and transgressive boundary orientations, may well be meaningless or very difficult to interpret in a rock like dolerite. Further, columns may only be defined reliably on the basis of basic morphology, confinement of other fractures and curvature of faces separating facets.

The formation of tessellated platforms and the visually attractive patterns requires near horizontal bedding and an extensive weathering process. Most joints on such platforms at Pirates Bay are surficial in origin, grow downward and are "modern" developments. The joints do appear to be the result of application of regional stresses to a rock package unloaded by uplift and exposure. There is an element of prestressing in the rocks, which leads to bias upon unloading and weathering. Some regional and tectonic joints do exist, but these are not directly responsible for, nor related to the tessellations, and most disrupt the patterns. Near E-W fractures are regionally dominant, and many important coastal landforms or alignments are controlled by them although negligible displacement is associated with these features. An underlying dextral shear in the Lufra area, whose position is now marked by Eaglehawk Bay, is thought to rejuvenate fundamental N-S components.

Weathering processes are crucial to development of surface cracking and ultimately, within the subtly imposed stress field, linkage of cracks. These grow downward into and along the beds as the weathering process acts upon them. The surface featuring of each formed block is the combined result of physical and chemical weathering processes. Fracture origin of this style, with a fundamental applied bias, can lead to an apparent sub-orthogonal regional pattern which mirrors the underlying shear cause.

In these terms, the joint development in both dolerite intrusions and pavements is comparable, with a fundamental in-built bias related to pre-existing structures, followed by selectively eroded bias to produce topographic features and apparent regional fracture grain. Such an explanation would account for the clear differences in joint patterns in adjacent areas (Pirates Bay, Hauy--Munro Bight) and other areas (including Single Hill). A comprehensive review of joints in southern Tasmania is needed to determine whether Carey's $(1958,1976)$ suggestion is valid regionally, but the dolerite cliffs and pavements of the Tasman Peninsula suggest that many gross fracture patterns may result from selective erosion determined by original alignment bias and not a regular, imposed fracture set.

\section{ACKNOWLEDGEMENTS}

I am grateful for useful discussions during the 50th anniversary celebrations of the Geology Department visit to the Tessellated Pavement in 1996 and subsequently with Dr M.R. Banks. Field assistance was provided by Marcia Solomon.

\section{REFERENCES}

Aydin, A. \& DeGraff, J.M., 1988: Evolution of polygonal fracture patterns in lava flows. Science 239: 471-476.

BANKS, M.R., 1998: Changing visions of our mountain. In Terry, I. \& Evans, K. (Eds): HOBART'S HISTORY: THE FIRST TWO HUNDRED YEARS. Pap. Proc. Conf. Prof. Hist. Assoc. Tasm. 4 Oct. 1997: 7-18.

Banks, M.R. \& Leaman, D.E., 1999: Charles Darwin's field notes on the geology of Hobart Town - a modern appraisal. Pap. Proc. Roy. Soc. Tasm. 133(1): 29-50.

Banks, M.R., Colhoun, E.A., Ford, R.J. \& Williams, E., 1989: A reconnaissance geology and geomorphology of the Tasman Peninsula. In Smith, S.J. (Ed.):IS HISTORY ENOUGH? PAST, PRESENT AND FUTURE USE OF THE RESOURCES OF TASMAN PENINSULA. Royal Society of Tasmania, Hobart: 7-23.

Branagan, D.F. \& Cairns, H.C., 1993: Tesselated Pavements in the Sydney Region, New South Wales. J. Proc. R. Soc. NSW 126: 63-72.

CAREY, S.W., 1958: Note on the columnar jointing in Tasmanian dolerite. In DOLERITE, A SYMPOSIUM. University of Tasmania, Hobart: 229-230.

CAREY, S.W., 1976: THE EXPANDING EARTH. Elsevier: $488 \mathrm{pp}$.

Crarke, M.J., 1989: Lower Parmeener Supergroup. In Burrett, C.F. \& Martin, E.L. (Eds): GEOLOGY AND MINERAL RESOURCES OF TASMANIA. Geol. Soc. Aust. Spec. Publ. 15: 293-309.

DAVID, T.W.E. \& BROWNE, W.R., 1950: THE GEOLOGY OF THE COMMONWEALTH OF AUSTRALIA. Vol.2. Edward Arnold, London: pl. 76 (opp. p. 113).

Davidson, J.K., 1997: Synchronous compressional pulses in extensional basins. Mar. Petrol. Geol. 14: 513-549.

DeGrafF, J.M. \& Aydin, A., 1993: Effect of thermal regime on growth increments and spacing of contraction joints in basaltic lava. J. Geophys. Res. 98: 6411-6430.

ForsyTh, S.M., 1984: OATLANDS, TASMANIA. Tasm. Dep. Mines Geol. Atlas 1:50000 Series. Explanatory Notes. Sheet 68 (8313S).

HALE, G.E.A., 1958: Some aspects of jointing and decomposition in Tasmanian dolerites. In DOLERITE, A SYMPOSIUM. University of Tasmania, Hobart: 184-196.

Hergt, J.M., McDougall, I., Banks, M.R. \& Green, D.H., 1989: Jurassic dolerite. In Burrett, C.F. \& Martin, E.L. (Eds): GEOLOGY AND MINERAL RESOURCES OF TASMANIA. Geol. Soc. Aust. Spec. Publ. 15: 375-381.

Hil.t, P.A., 1964: Curviplanar (radial, bow-tie, festoon) and concentric jointing in Jurassic dolerite Mersey Bluff, Tasmania. J. Geol. 73: 255-270.

HILLS, E.S., 1963: ELEMENTS OF STRUCTURAL GEOLOGY. Methuen, London: $483 \mathrm{pp}$.

HOLMES, A., 1965: PRINCIPLES OF PHYSICAL GEOLOGY. Nelson, London: $1288 \mathrm{pp}$.

JAEGER, J.C., 1958: The solidification and cooling of intrusive sheets. In DOLERITE, A SYMPOSIUM. University of Tasmania, Hobart: $77-87$. 
KeLLEY, V.C., 1987: Joints and fractures. In Seyfert, C.K. (Ed.): THE ENCYCLOPEDIA OF STRUCTURAL GEOLOGY AND PLATE TECTONICS. Encycl. Earth Sci. Ser. 10. Van Nostrand, New York: 876 pp.

LEAMAN, D.E., 1972: The engineering properties of Tasmanian dolerite with particular reference to the route of the Bell Bay Railway. Tech. Rep. Dep. Mines Tasm. 16: 148-163.

Leaman, D.E., 1978: Some thoughts on dolerite intrusions with particular reference to marginal features. Rep. Geol. Surv. Tasm. 1978/30.

Leaman, D.E., 1997a: Features of Jurassic dolerite intrusions at Cape Surville, Lynwood, Single Hill and Mount Nelson, Tasmania. Pap. Proc. R. Soc. Tasm. 131: 13-20.

LEAMAN, D.E., 1997b: Gravity survey and structure of the Forestier Peninsula, Southern Tasmania. Pap. Proc. Roy. Soc. Tasm. 131: 77-84.

LeAman, D.E. \& RichardSON, R.G., 1990: Tasmanian crustal features. Abstr. 10th Australian Geological Convention, Hobart: 100-101.
Pollard, D.D., \& Aydin, A., 1988: Progress in undetstanding of jointing over the past century. Bull. Geol. Soc. Am. 100: $1181-1204$.

Segall, P. \& Pollard, D.D., 1983a: Joint formation in granitic rocks of the Sierra Nevada. Bull. Geol. Soc. Am. 94: 563575.

Segall, P. \& Pollard, D.D., 1983b: Nucleation and growth of strike-slip faults in granite. J. Geophys. Res. 88: 555-568.

Segall, P., McKee, E.H., Martel, S.J. \& Turrin, B.D., 1990: Late Cretaceous age of fractures in the Sierra Nevada batholith, California. Geology 18: 1248-1251.

U.S. Geological Survey, 1984: A summary of geologic studies to January 1, 1983 of a potential high-level radioactive waste repository site at Yucca Mountain, Southern Nye County, Nevada. USGS open file report 84-792. USGS Denver, Colorado: 103 pp.

(accepted 5 July 1999) 